\title{
Enhancing Urban Water Supply through Rainwater Collection in Enugu Town, Nigeria
}

\author{
Emma E. Ezenwaji1', Chukwudi P. Nzoiwu2 ${ }^{2}$ Bede M. Eduputa ${ }^{3}$ \\ ${ }^{1}$ Department of Geography and Meteorology, Nnamdi Azikiwe University, Awka, Nigeria \\ ${ }^{2}$ Department of Geography, University of Ibadan, Ibadan, Nigeria \\ ${ }^{3}$ Department of Environmental Management, Nnamdi Azikiwe University, Awka, Nigeria \\ Email: emmaezenwaji@gmail.com
}

Received 31 October 2015; accepted 22 February 2016; published 25 February 2016

Copyright (C) 2016 by authors and Scientific Research Publishing Inc.

This work is licensed under the Creative Commons Attribution International License (CC BY). http://creativecommons.org/licenses/by/4.0/

(C) (i) Open Access

\section{Abstract}

The aim of the study was to assess the contributions of rainwater to water supply of Enugu metropolitan area. To achieve this aim 42 years rainfall data (1971-2012) were collected from Enugu airport as well as the catchment area of house roofs in the town from the Ministries of Urban Development and Housing. Meteorological data (Rainfall) obtained were tested for normality, while ANOVA technique tested rainfall variance among four decades (70's, 80's, 90's and 20's) of the study. Trend and Regression analyses were utilized for the long range data. Finally, augmented Dickey-Fuller test (stationarity test) revealed whether the independent variable explained the dependent. Result shows that rainfall data were normally distributed and not significantly different in the four decades studied. The trend shows a general increase in rainfall amount over 42 years while the regression model indicated that for every one year, rainfall amount increases by $1.19 \mathrm{~mm}$ with a base constant of $113.2 \mathrm{~mm}$. The amount of water realized from rainfall in the city for 2015, 2016 and 2017 based on catchment area of 102,500,000 $\mathrm{m}^{2}$ is $37,578,000,37,742,000$ and $37,967,000,315$ litres per annum, representing about $3 \%$ of total water supply in the town equivalent to commercial water demand. Recommendations include revision of the existing water policy to include mandating residents and shop owners to install catchment gutters to collect rain water from their roofs, promotion of a programme of rainwater harvesting against certain barriers with respect to socio-cultural beliefs and attitudes etc.

\section{Keywords}

Airport, Decades, Model, Normality, Urban 


\section{Introduction}

The problems of inadequate water supply to all sectors in Enugu urban area continue to worry relevant government authorities and are widely recognized by researchers: [1]-[6]. The ever increasing geographical expansion of the city together with its geometrical growth in population has made the situation even worse.

Today, the urban water supply in the town only satisfies only 58\% of demand leaving a yawning deficiency gap of $42 \%$ to be filled [3] [7]. [6] had attempted to determine the reasons for this gap in the residential sector and concluded that the inadequacy of surface water as a result of massive silting of the river bed which impairs proper river discharge, the high level of pollution of the river water bed and the nature of the city's geological formation limit ground water exploitation. It has, therefore, become necessary to explore other available options of water supply sources besides the surface water and ground water. One option that has so much been neglected and at the same time attracted very poor attention over the years is the rain water source [8]. There are several reasons for the rediscovery of this simple yet highly appropriate method of urban water supply. Perhaps, the most significant is the growing number of potential catchment surfaces available in urban areas which are amply provided by zinc roofs in Enugu urban area. Rainwater collection is always one available option waiting to be exploited. Apart from this, the availability of impervious surfaces in the urban area generates a lot of flood water whenever it rains, which destroys life and property. Rainwater harvesting is one sure way of preventing these enormous losses of water through flood.

Rainwater as a source of water supply has its problems, one of which is the uncertainty associated with both its spatial and temporal variations [9] [10]. Furthermore, rainwater is sometimes of poor quality especially when it is infested with atmospheric dusts and other harmful substances during its free fall as well as the quality of the catchment surfaces [4] [11] [12]. Others can be linked to the poor materials and construction techniques for rainwater harvesting, as well as the best way to finance rainwater projects [13]-[15]. In spite of these, rainwater provides one of the cheapest sources of water supply which can easily be relied on in a water supply shortage area such as Enugu. Despite all the above, the study of rainwater and its contributions to urban water supply in Enugu has been scanty.

The paper, therefore, seeks to examine the rainfall trend of Enugu urban area and determine its contribution to water supply.

\section{Materials and Methods}

\subsection{Area of Study}

Enugu urban area is roughly located between Latitudes $06^{\circ} 30^{\prime} \mathrm{N}$ and $06^{\circ} 40^{\prime} \mathrm{N}$ and Longitudes $07^{\circ} 20^{\prime} \mathrm{E}$ and $07^{\circ} 35^{\prime} \mathrm{E}$. The urban area covers three local government areas an nine principal districts, some of them are Trans-Ekulu, Uwani, Coal Camp (Ogbaete) Achala layout, New heaven, Ogui etc. (Figure 1). According to [16] the population of the town was 772,664 in 2006 while its 2014 population was projected to 910,003 using the authorized 3\% growth rate for urban areas in Nigeria.

In terms of geology, the town lies in the eastern Nigeria sedimentary basin, underlain by Enugu shales, lower coal measure (Mamu formation) and false bedded sandstone (Ajalli formation). Its topographical features are classified into two; the escarpment zone, the plains and lowlands of Cross River Basin. Average maximum temperature is usually a little above $27^{\circ} \mathrm{C}$ all over the year although it sometimes exhibits peak of up to $36^{\circ} \mathrm{C}$ in March, which is usually the hottest month of any year. Average annual rainfall is about $1800 \mathrm{~mm}$ but over $70 \%$ of the amounts fall in four months, between June and September. The urban area sources its water supply mainly from Ekulu and Asata rivers boreholes as well as shallow wells around Abakpa-Nike, Emene, New Haven and parts of Independence Layout where the geological formation permits.

\subsection{Data Collection and Analysis}

The study relied on 42 years rainfall data from 1971-2012 from the Enugu Airport, while data for the total catchment of the house roofs in the town was obtained from the Ministries of Urban Development and Housing. Data were statistically analysed using the statistical package for the Social Sciences (SPSS Version 20). Statistical methods utilized are Jacque-Bera normality test, ANOVA, Dickey Fuller test for stationarity and time series analysis. Jacque-Bera normality test was employed to check the normality of the error term or residual so as to ascertain whether the assumption of normality of the regression analysis was satisfied. ANOVA was used to 


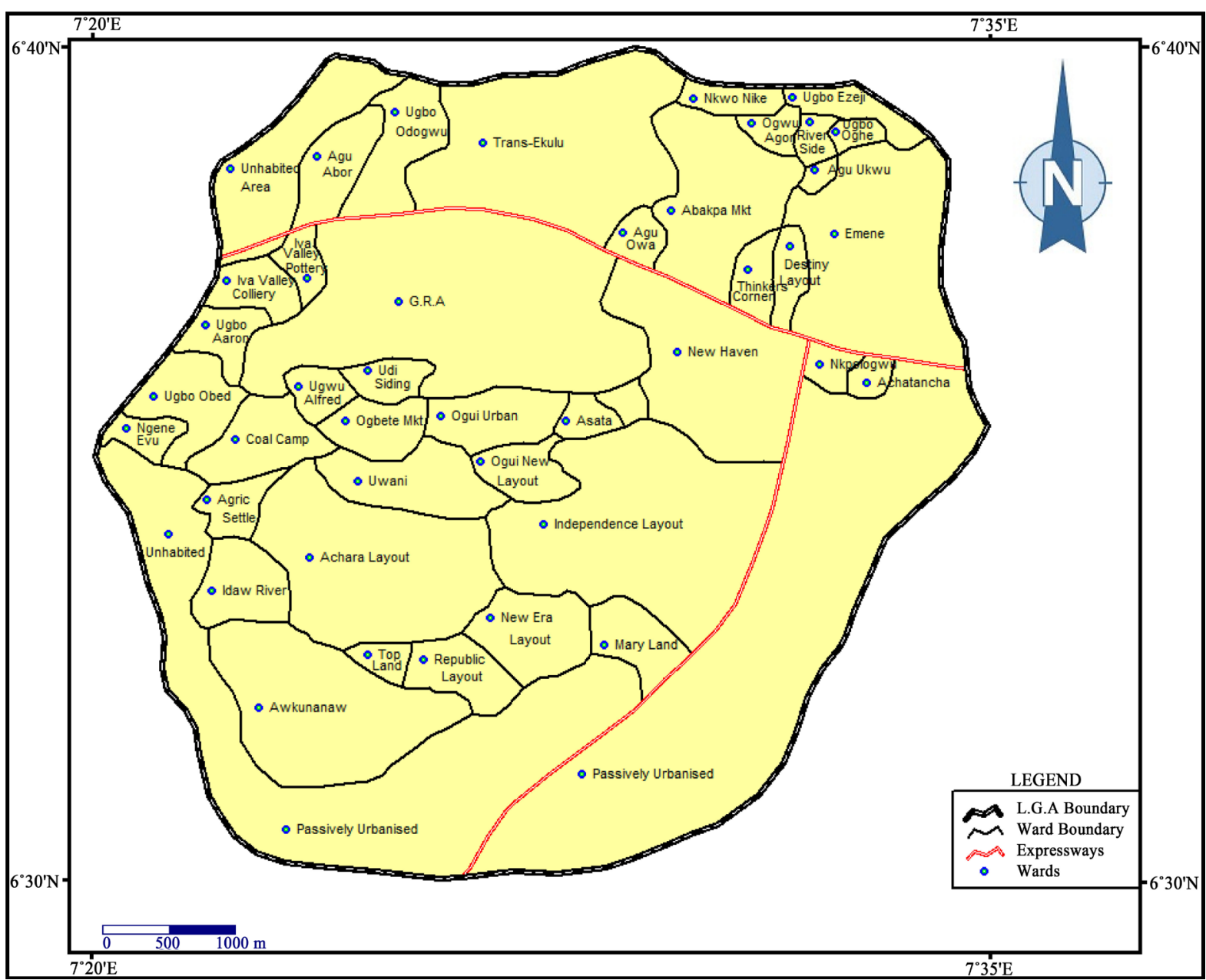

Figure 1. Map of Enugu urban area.

test the existence of significant difference among four decades (70's, 80's, 90's and 20's) in which our data were subdivided and analysed. Dickey-Fuller test for unit root (stationary test) was employed to test whether the independent variable (time) adequately explained the dependent variable (rainfall). Time series analysis was utilized to calculate the rainfall trend over the study period, while the regression analysis determined the rate of trend. The potential amount of water to be supplied from available rainfall amounts was calculated using the formula

$$
\mathrm{S}=\mathrm{R} \times \mathrm{A} \times \mathrm{Cr}
$$

where $\mathrm{S}$ is the mean rainwater supply in $\mathrm{m}^{3} \mathrm{R}$ is the mean annual rainfall in $\mathrm{mm}$ : A is the catchment area in $\mathrm{m}^{2}$ and $\mathrm{Cr}$ is the runoff coefficient which for sloping roof is 0.80 . This sloping surface harvests up to about $50 \%$ more rainwater than flat roof and as such will be used in this work as nearly all the roofs in the exhibit relative degrees of slops.

\section{Result and Discussion}

\subsection{Results}

The Jacque-Bera normality test shows that the data was normally distributed. On the strength of this, ANOVA which is a parametric test applied to the data produced the result in Table 1.

In Table 1 , p-value is less than 0.01 which implies that the test is significant at $1 \%$ level meaning that there exists enough evidence to conclude that the amount of rainfall in the urban area vary significantly among the four decades examined. Trend analysis plot was performed (Figure 2) which yielded the regression model for 
Table 1. One-way ANOVA of rainfall data in Enugu urban area.

\begin{tabular}{cccccc}
\hline Source & Df & Ss & Ms & F & P \\
\hline Factors & 3 & 8013 & 2671 & 7.57 & 0.000 \\
Error & 36 & 12,705 & 353 & & \\
Total & 39 & 20,719 & & & \\
\hline
\end{tabular}

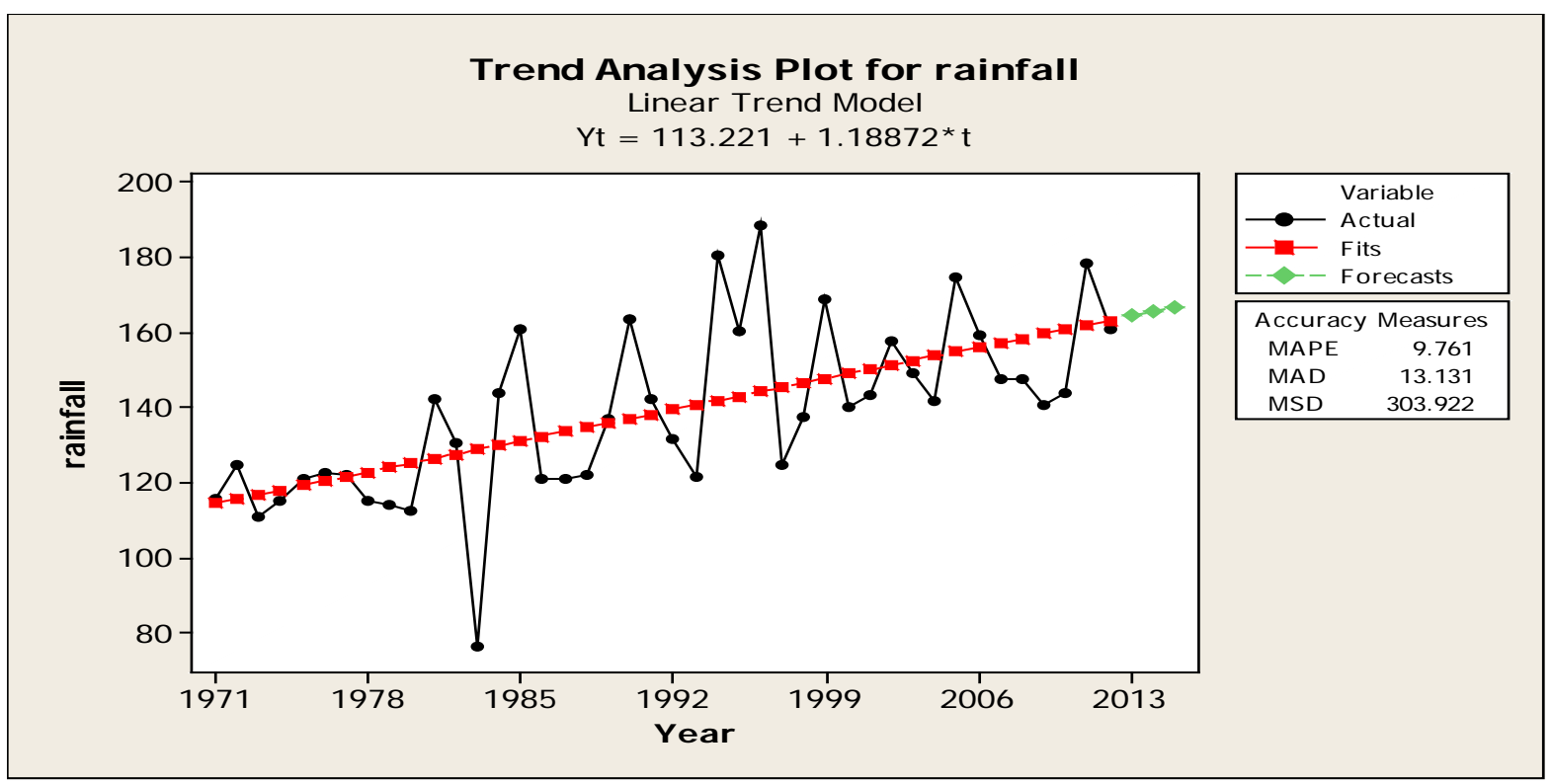

Figure 2. Trend analysis plot of rainfall.

the town (Equation (2)).

$$
\mathrm{Y}=113.221+1.887 \mathrm{t}
$$

The trend plot analysis shows that rainfall in the urban area is on a steady increase. There are three measure of accuracy in the plot namely MAPE, MAD, and MSI), but among them MSD (Mean Square Deviation) which is more sensitive measure than others was used to determine the plot accuracy. It shows that considering the size of our data, an MSD value of 303.922 reveals a considerable high accuracy of the trend. The regression model produced show that one-unit increase in the number of years results in $1.887 \mathrm{~mm}$ of rainfall. However, it is necessary to show how the residuals behaved in relation to the fitted regression line using normal probability plot of residuals (Figure 3).

It is found that considerable number of residual points is closely fitted to the line, indicating the accuracy of the model. On the strength, it can be reasonably stated that the rainfall of Enugu will continue to increase by the year. The five year rainfall forecast value for the town shows the following values against each year (Table 2).

Table 2 shows plainly the absolute increases in rainfall values over the projected years. The Dickey-Fuller stationary lest revealed that the independent variable (time) explained the dependent variable (Table 3) assuring the forecasted values.

The $\mathrm{p}$-value for $\mathrm{Z}(\mathrm{t})$ which is 0.9514 is higher than the critical value of 0.05 meaning that time (years) adequately explained the observed increases in rainfall amount of the city. Furthermore, with a total roof catchment area of $102,500,000 \mathrm{~m}^{2}$, the town will source the following water supply amounts from rainfall for 2015,2016 and 2017 using formula 5 as follows (Table 4).

From Table 4, it could be seen that the total daily rainwater for 2015 contribution to Enugu urban water supply is 37,518,000 litres/day in 2015, 37,742,000 litres/day in 2016 and 37,967,000 litres/day in 2017 respectively.

\subsection{Discussion}

The result achieved in this study show the need to embrace rainwater collection as one of the viable sources of 


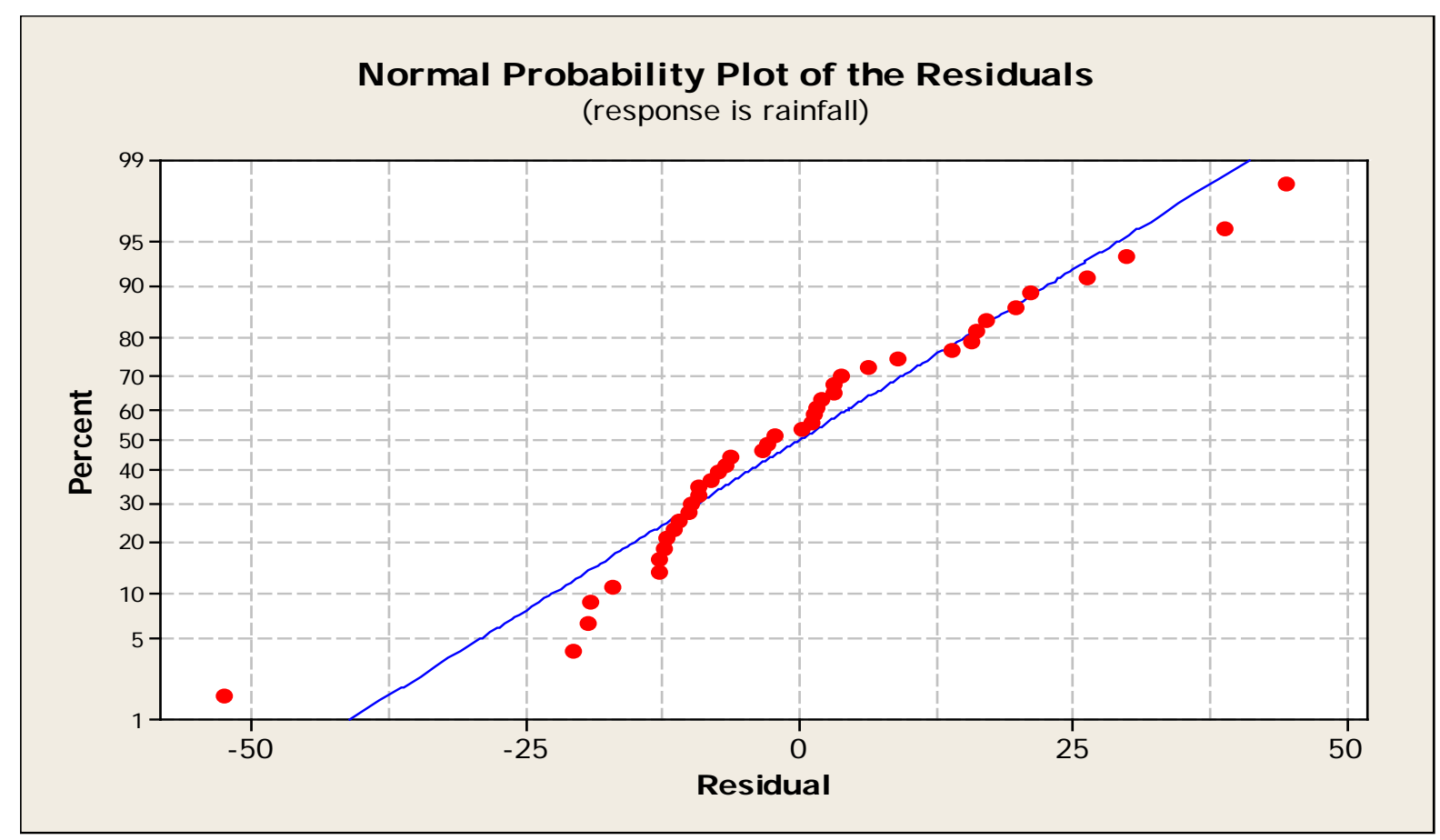

Figure 3. Normal probability plot of the residuals.

Table 2. Forecast values of rainfall in Enugu urban area, Nigeria.

\begin{tabular}{cc}
\hline Year & Forecasted Rainfall Value \\
\hline 2013 & 164.336 \\
2014 & 165.525 \\
2015 & 166.713 \\
2016 & 167.901 \\
2017 & 169.089 \\
\hline
\end{tabular}

Table 3. Augmented dickey-fuller test.

\begin{tabular}{lcccc}
\hline & \multicolumn{4}{c}{ Interpolated Dickey-Fuller } \\
\cline { 2 - 5 } & Test Statistic & \% Critical Value & $5 \%$ Critical Value & $10 \%$ Critical Value \\
\hline $\mathrm{Z}(\mathrm{t})$ & -0.943 & -4.325 & -3.576 & -3.226 \\
\hline
\end{tabular}

Mackinnon Approximated P-Value for $\mathrm{Z}(\mathrm{t})=0.9514$.

Table 4. Yearly and daily contribution of rainwater to Enugu urban water supply.

\begin{tabular}{ccc}
\hline Year & $\begin{array}{c}\text { Annual Water Supply } \\
(\mathrm{S}=\mathrm{R} \times \mathrm{A} \times \mathrm{Cr}) \text { Equation (1) }\end{array}$ & Daily Water Supply $\left[\frac{\text { Total Amount }}{\text { No. of days in the year }}\right]$ \\
\hline 2015 & $13,694,000 \mathrm{~m}^{3}$ & $37,518 \mathrm{~m}^{3}(37,518,000$ litres/day) \\
2016 & $13,776,000 \mathrm{~m}^{3}$ & $37,742 \mathrm{~m}^{3}(37,742,000$ litres/day) \\
2017 & $13,858,000 \mathrm{~m}^{3}$ & $37,967 \mathrm{~m}^{3}(37,967,000$ litres/day $)$ \\
\hline
\end{tabular}

water supply in Enugu urban area. The city has an ample supply of rainwater that should not be allowed to waste as flood in some instances with its attendant high magnitude that destroys life and property. The need to determine the direction of rainfall movement in the city over these 42 years made us to run a trend analysis which we found to be generally moving up. This result was further made clearer by the regression model which reveals 
that a unit increase in years results in $1.189 \mathrm{~mm}$ increase in rainfall. This is an indication that some degree of global warming is at work since increase in temperature creates Urban Heat Islands (UHI) which usually results in convectional (thermal) rainfall the type that characterizes the urban area [17]. Convectional rainfall is usually spotty with high intensity and this makes it to generate violent floods on the city's impervious surfaces which apart from destroying life and properly creates gully erosion. These impervious surfaces are ready platforms for the collection of rainwater. Enugu with a land area of $145 \mathrm{sqkms}$ has about 145 million sq meters $\left(1,000,000 \mathrm{~m}^{2}\right.$ to lsqkm). Out of this land area, the collective roof catchment area is $102,500,000 \mathrm{~m}^{2}$ or $70.7 \%$ of the geographical extent of the city. This is a large area that when properly harnessed for rainwater harvesting will contribute immensely to the city's total water supply of 37,518,000 litres per day. This amount of water is about $18 \%$ of 207 Million litres per day (MLD) which is the total water demand in the town and 32\% of 121 MLD which is its present amount of water supply. The fact that our stationarity test confirmed that our independent variable (time) adequately explained our dependent variable (rainfall) goes to authenticate the regression model that produced the predicted rainfall value which was employed to compute the city's daily water supply from rainwater. The total amount of water supply from this source (37.5 MLD) is much when it is realized that it would be able to meet the commercial and public institutions sectors water demand of about 28 MLD and even have a surplus of 9.5 MLD [3] [18].

The ANOVA test showed that rainfall varies within the four decades used for the analysis with the last two decades (1990's and 2000's) having the largest amounts, pointing to a higher future occurrence. What this means is that instead of allowing rainfall to be a problem because of its chances of having future destructive flood, we should turn it into greater opportunities with the expectation of realizing higher water supply amounts for the urban area in future.

\section{Conclusion}

This paper has attempted to determine the contributions of rainwater to urban water supply in Enugu and found that rainfall amounts have continued to increase over 42 years. Water from rainfall has hitherto been wasting and causing havoc as a result of the consequent flooding and subsequent erosion of urban land. The paper established the total amount of water supply for the city that could be realized from rainwater source and the percentages of the total water demand and supply that could be met from this source as a result. The harnessing of rainwater will satisfy both commercial and public institutions water demand as has already been indicated. This, therefore, calls for urgent necessary action to properly harness it by both the government and consumers to achieve this desired goal.

\section{Recommendations}

Rainwater is an important source of water supply despite its past neglects. In view of this, a number of recommendations are made to ensure its proper harnessing to enhance water supply of the city.

1) The consumers should be sensitized by relevant authorities to rely on this ready and easily accessible source of water supply, considering that presently certain socio-cultural beliefs prevent some consumers from using it.

2) The state government should revise the state water policy to include water supply from rainwater. Such a policy will ensure that all residential, commercial and industrial buildings will have their roofs fitted with appropriate gutters and down pipes to collect and direct water to the storage tank to be installed for use.

3) The state government should subsidize the cost of plastic storage tanks for it to enable consumers purchase to be affordable to consumers. This is the only way majority of people will be able to install it to easily access rainwater.

4) Rainfall prediction should be made available to the Enugu State Water Corporation by NIMET to help it estimate the amount of water to he realized from that source every year.

\section{References}

[1] Anyadike, R.N.C. and Ibeziakor, M.N. (1987) The Spatial Structure of Residential Water Demand in Enugu Urban Area, Nigeria. The Nigerian Journal of Social Studies, 4, 1-7.

[2] Nnodu, V.C. and Ilo, I.C. (2000) Comparative Quality Evaluation of Sources of Domestic Water Supply in Enugu Urban. Environmental Review, 3, 215-231. 
[3] Ezenwaji, E.E. (2009) Municipal and Industrial Water Demand and Supply in Enugu Urban Area, Nigeria. Unpublished PhD Thesis, University of Nigeria, Nsukka.

[4] Ezenwaji, E.E., Okoye, A.C. and Otti, V.I. (2013) Effects of Gas Flaring on Rainwater Quality in Bayelsa State: Eastern Niger-Delta Region, Nigeria. Journal of Toxicology and Environmental Health Sciences, 5, 97-105. http://dx.doi.org/10.5897/JTEHS2013.0265

[5] Igboanugo, R.I. (2011) Municipal Water Supply in Enugu Urban Area. Unpublished B.Sc Dissertation, Nnamdi Azikiwe University, Awka.

[6] Ezenwaji, E.E., Phil-Eze, P.O. and Enete, I.C. (2014) A Multivariate Statistical Analysis of Public Institutions Water Demand in Enugu Urban Area. The Nigerian Geographical Journal, 10, 68-80.

[7] Okere, G.A. (2014) Estimating Water Demand in Enugu Urban Area with a Component Model. Water Supply and Environment, 9, 101-107.

[8] Gould, J. and Nissan-Peterson, E. (2008) Rainwater Catchment Systems for Domestic Supply. Practical Action, Warwickshire.

[9] Nnaji, A.O. (2010) Implications of Recent Climate Variability for Urban Water Supply and Sustenance in Owerri, Imo State. First National Workshop, Environment Development Initiative for Africa (EDIA), Awka, 8-10 June 2010.

[10] Onaibe, M. (2013) Spatial Variations of Rainfall over Enugu Urban Area, Nigeria. Journal of Water Supply, 3, 107114.

[11] Kamai, D.A. (2013) Rainwater Quality and Environmental Cleaning. Health and Environment, 3, 91-100.

[12] Akubi, J.C. (2014) Modeling Rainwater Quality in Lagos. Journal of Urban Health, 6, 110-119.

[13] Bang, Y., Brown, D. and Onwubiko, A.O. (1981) Prevalence of Larvae of Potential Yellow Fever in Domestic Water Containers in South-Fast Nigeria. Bulletin of the World Health Organization, 59, 107-114.

[14] Bastermeyer, T. and Lee, M. (1992) Drinking Water Deterioration: An Urgent Problem. Waterlines, 11, 9-12. http://dx.doi.org/10.3362/0262-8104.1992.022

[15] Hewison, K. (1996) Public Health Aspects of Rural Wale. Supply and Environmental Sanitation in North East Thailand and the Lao PDR, in Mekong Basin Natural Resource Management Project. Report for AUSAID, Murdoch University and University of Sydney.

[16] National Population Commission (2006) 2006 Population Statistics. National Bureau of Statistics, Abuja.

[17] Enete, I.C. and Alabi, M.O. (2012) Characteristics of Urban Heat Island in Enugu Urban during Rainy Season. Ethiopian Journal of Environmental Studies and Management, 5. http://dx.doi.org/10.4314/ejesm.v5i4.8

[18] Ezenwaji, E.E., Enete, I.C. and Eduputa, B.M. (2013) An Empirical Analysis of Socio-Economic and Physical Factors Affecting Industrial Water Demand in Enugu Urban Area, Nigeria. Social Review, 1, 74-83. 